stay in hospital can only be a notional figure. The cost of cataract surgery was indeed based upon the figures given in the Welsh Office publication as $£ 139$ per inpatient week in acute non-teaching hospitals and $£ 214$ per inpatient week in acute teaching hospitals, but Dr Phillips-Miles has failed to realise that the "cost" of cataract surgery was expressed as the cost per patient and not as the cost per inpatient week. Furthermore, these figure were the mean cost per patient in the areas concerned, derived from the mean duration of stay, and were certainly not calculated from the extremes that he suggests.

The unit cost of a hospital bed per week is unlikely to vary much between specialties or with the duration of stay of individual patients and will always be sustained by the longsuffering taxpayer. The marginal cost of any unnecessary delay in discharging patients is borne by those on the waiting lists, whose average age is likely to be over 70 and for whom waiting time is important. The real cost of cataract surgery lies not in a contrived figure based upon length of stay or aggregated statistics but in the human cost of those patients with cataracts who are awaiting surgery.

H B J CHISHIC

Welsh National School of Medicine,

Cardiff

Intended place of delivery and perinatal outcome

SIR,-I am indebted to Mrs Marjorie Tew (29 April, p 1139) for discussing in such detail the paper I wrote with Professor N R Butler (25 March, p 763) and grateful for this opportunity to reply to her argument.

She first criticises the whole concept of analysing the data according to where the patient was booked for delivery rather than where she was actually delivered. The difficulty arises in that group of women who were booked for home delivery but were transferred for delivery in a consultant unit. This small group of deliveries has a very high perinatal mortality rate (not surprisingly-it seems reasonable to assume that they were transferred because the general practitioner had recognised some imminent danger). It is our contention that this group should be included in the home-booked group, transfer in labour being one of the dangers inherent in such a booking. The analysis then tests the hypothesis that the place of booking has no effect on perinata mortality (that is, we start with the null hypothesis). Mrs Tew appears to think this is begging the question. Her argument is difficult to follow. To produce an analogy from adult medicine: if one were assessing the efficacy of place of care in a randomised controlled trial for patients who had had a myocardial infarct one would not omit from the domiciliary group those patients who were being cared for at home but had suddenly deteriorated, were transferred to hospital, and died.

Mrs Tew quibbles about the levels of statistical significance of the beneficial effect found in patients booked for NHS consultant units in each of our three groups. The fact that in each group the effect was in the same direction and of the same order of magnitude is the important and, I think, wholly convincing fact.

The original paper included a graph to show that the national stillbirth rate in domiciliary deliveries has actually been rising since 1970. The figure was intended to contrast trends, but there has been some suggestion that it was misleading. It has never been our contention that the stillbirth rate in home deliveries was not much lower than that in hospital deliveries-for obvious reasons (see the analogy above)

Even were it not for transfers from home to hospital late in pregnancy, the result of selecting the women at highest risk over the years should automatically result in an apparent secular fall in stillbirth rate. This paradox has been discussed fully by Yudkin and is illustrated in the table. Here I have taken a hypothetical situation in which the number of hospital deliveries has increased over a period of five years and assumed that, given the choice, the women at highest risk would be selected for hospital delivery. It can be seen that this automatically results in falling stillbirth rates in hospital and domiciliary deliveries. The worrying point about the graph we showed is that the stillbirth rate among domiciliary deliveries has actually been rising since 1970 in spite of the falling proportion of such cases. This indicates either that the assessment of high-risk patients has deteriorated or that the care of women delivered at home is not as good as it used to be. Both possibilities give cause for concern

JEAN FEDRICK

Unit of Clinical Epidemiology,
Oxford Record Linkage Study, Oxford Yudkin, P, British fournal of Obstetrics and Gynae
cology, 1976, 83, 603.

\section{The therapeutic Smartie}

SIR,-Now that I have received a letter from the Secretary of State for Social Services and the Chairman of Council of the BMA regarding the need for economy in prescribing tranquillisers I feel this may be an opportune moment to publish the fact that I am seriously using tubes of Smarties in order to help my patients recognise their oral needs to allay anxiety and to give them a way of communicating with me that they are feeling depressed and worried.

There are many adolescents who are not

Hypothetical situation in an area with 10000 deliveries per year and an increasing proportion of hospital deliveries

\begin{tabular}{|c|c|c|c|c|c|c|c|c|c|}
\hline \multirow[b]{2}{*}{ Year } & \multicolumn{3}{|c|}{ Hospital } & \multicolumn{3}{|c|}{ Home } & \multicolumn{3}{|c|}{ All } \\
\hline & $\begin{array}{c}\text { No of } \\
\text { deliveries }\end{array}$ & $\begin{array}{c}\text { No of } \\
\text { stillbirths }\end{array}$ & $\begin{array}{c}\text { Stillbirth } \\
\text { rate per } \\
1000\end{array}$ & $\begin{array}{c}\text { No of } \\
\text { deliveries }\end{array}$ & $\begin{array}{l}\text { No of } \\
\text { stillbirths }\end{array}$ & $\begin{array}{c}\text { Stillbirth } \\
\text { rate per } \\
1000\end{array}$ & $\begin{array}{c}\text { No of } \\
\text { deliveries }\end{array}$ & $\begin{array}{c}\text { No of } \\
\text { stillbirths }\end{array}$ & $\begin{array}{c}\text { Stillbirth } \\
\text { rate per } \\
1000\end{array}$ \\
\hline $\begin{array}{l}1 \\
2 \\
3 \\
4 \\
5\end{array}$ & $\begin{array}{l}1000 \\
2000 \\
3000 \\
4000 \\
5000\end{array}$ & $\begin{array}{l}50 \\
70 \\
80 \\
85 \\
89\end{array}$ & $\begin{array}{l}50 \cdot 0 \\
35 \cdot 0 \\
26 \cdot 7 \\
21 \cdot 3 \\
17 \cdot 8\end{array}$ & $\begin{array}{l}9000 \\
8000 \\
7000 \\
6000 \\
5000\end{array}$ & $\begin{array}{l}50 \\
30 \\
20 \\
15 \\
11\end{array}$ & $\begin{array}{l}5 \cdot 5 \\
3 \cdot 8 \\
2 \cdot 9 \\
2 \cdot 5 \\
2 \cdot 2\end{array}$ & $\begin{array}{l}10000 \\
10000 \\
10000 \\
10000 \\
10000\end{array}$ & $\begin{array}{l}100 \\
100 \\
100 \\
100 \\
100\end{array}$ & $\begin{array}{l}10 \\
10 \\
10 \\
10 \\
10\end{array}$ \\
\hline
\end{tabular}

suffering from endogenous depression but have social problems which burden them, and they make an appeal for help by taking a handful of the nearest tablets. But for those young people for whom I prescribe Smarties, two three times a day and overdoses when required, I am quite sure that this gift from me to them has reduced the number of attempted suicides and the need for ambulance and hospital attention, has enabled group therapy to be more meaningful, and is more valuable than the usual placebo.

My colleagues tease me, but I have found that some social workers have copied the idea, and, when given with concern and care, it can be a valuable adjunct to psychotherapy.

Josephine M Lomax Simpson

South London Hospital for Women and Children,

\section{Klebsiella ozaenae in bronchiectasis}

SIR,-In her interesting article on bronchiectasis and cystic fibrosis Dr Margaret E Hodson (15 April, p 971) mentions the important pathogens in bronchiectasis. She does not, however, mention the presence of Klebsiella ozaenae in bronchiectasis.

Since the observation ${ }^{1}$ that capsular type 4 $K$ ozaenae seems to be associated with chronic secondary infection in destructive disorders such as cystic fibrosis or bronchiectasis as opposed to chronic bronchitis I have always queried, when reporting the presence of this organism in sputum, the existence of bronchiectasis in the patient from whom the organism was isolated. It has been both gratifying and, occasionally, surprising how often the presence of bronchiectasis has been confirmed or, in fact, revealed in patients about whom such an inquiry was made. I think it is useful that both clinical bacteriologists and clinicians should be aware of this association.

R J FALLON

Department of Laboratory

Medicine,
Ruchill Hospital, Glasgow

${ }^{1}$ Burns, M W, Lancet, 1968, 1, 383.

\section{Self-poisoning with beta-blockers}

SIR,-In your leading article on this subject (22 April, p 1010) you mention the use of intravenous isoprenaline. This drug certainly has its merits, but it should be remembered that the dose of isoprenaline which will produce an increase in heart rate due mainly to $\beta_{1}$ adrenoceptor stimulation will also reduce diastolic blood pressure by its action upon vascular $\beta_{2}$ adrenoceptors.

You also recommend the use of atropine $2-3 \mathrm{mg}$ intravenously in divided doses. It has been shown that atropine $0.04 \mathrm{mg} / \mathrm{kg}$ body weight is required to abolish vagal influences on the heart after therapeutic doses of betablockers. $^{23}$ We have recently observed that such a dose of atropine given as an intravenous bolus injection after propranolol or labetalol significantly increases systolic and diastolic pressures in normal healthy males (unpublished data). In addition, we have also shown that the same dose of atropine alone has a similar effect on blood pressure and can substantially potentiate the pressor effects of intravenous noradrenaline (unpublished 
data). Under these circumstances the usual effects of noradrenaline, causing marked reductions in heart rate and cardiac output, do not occur. Thus atropine, alone or after beta-blockers, can raise blood pressure and heart rate while maintaining cardiac output.

From these observations therefore we would endorse the use of atropine in doses of at least $3 \mathrm{mg}$ as bolus injections. Furthermore, as an alternative to isoprenaline in patients still hypotensive we would recommend graded infusions of noradrenaline to restore blood pressure provided atropine has been given previously. Under these circumstances heart rate and cardiac output are likely to be satisfactorily maintained and blood pressure restored.

D A RICHARDS BRIAN N C PRICHARD

University College Hospital Medical

School,

1 Richards, D A, Dobbs, J, and Prichard, B N C, British . Fournal of Clinical Pharmacology, 1978, (5)

Jose, A D, American Yournal of Cardiology, 1966, Chamberlain, D A, Turner, P, and Sneddon, J M,
Lancet, 1976, 2, 12.

\section{Facet joints and low back pain}

SIR, - My orthopaedic colleagues and I have been investigating this problem for several years and would strongly endorse the views of Mr J A Robertson and Mr A H G Murley (13 May, p 1283). However, we do not agree with the negative approach of "organised neglect." Conservative measures such as those outlined are always instituted in the first instance, but a significant number of patient are severely disabled by continuing pain. For these we recommend a facetal arthrogram, and, if local anaesthesia of the appropriate dorsal primary rami relieves the symptoms, proceed to rhizotomy with a radio frequency probe based on the work of Shealey. ${ }^{2} \operatorname{Dr} M \mathrm{E}$ Sluijter, of Amsterdam, and I have simplified this technique and performed it safely in over 200 cases in both the lumbar and cervical regions. Our results will be published shortly on completion of a survey one year after these procedures were undertaken.

MARK Mehta

Pain Relief Unit,

Norfolk and Norwich Hospital,

Norwich

Mehta, M, Intractuble Pain, p 242. London and Toronto, Saunders, 1973

${ }^{2}$ Shealey, G N, Journal of Neurosurgery, 1975, 63, 448.

\section{Methods of endometrial assessment}

SIR,-I was very interested to read the article by Mr J D Hutton and others on "Endometrial assessment with Isaacs cell sampler (15 April, $\mathrm{p}$ 947). I was, however, disappointed to see that the authors made an unfavourable comparison with the diagnostic potential of the Vabra curettage method based on, I suspect, non-comparable parameters.

In their discussion the authors state that "diagnosis of endometrial state was possible in $91^{\prime \prime}$ " of our patients compared with $77^{\circ}$, of similar age assessed by Vabra curettage," giving a reference to a clinical study by Whitehead et al ${ }^{1}$ which is "in press." This particular article can therefore not be commented on, but as all but one ${ }^{2}$ of the clinical articles on Vabra curettage (about 50 in all) are based on histological diagnosis, everything points towards the likelihood that the $77^{\circ}$ " in the study cited was similarly based on histological diagnosis. This figure, in fact, corresponds very well to the results cbtained from patients aged over 40 years by other authors. Thus Holt,; for example, was able to make a histological endometrial diagnosis in $80.1^{\circ}$ " of his patients. It is therefore probable that the authors, using the Isaacs cell sampler, were comparing a $91^{\circ} \circ$ satisfactory cytological diagnosis with a $77^{\circ}$, histological diagnosis. This, for obvious reasons, is not a valid comparison.

It should be noted that the Vabra method may in fact also be used for cytological examination of the endometrium. Jensen found that if a histological examination was not possible owing to inadequate aspirate (as, for example, in postmenopausal patients) a cytological examination was possible in $100^{\prime \prime}$ " of cases using the Vabra curettage method.

It is clearly important not only to distinguish between various endometrial biopsy methods but also to relate them to their specific diagnostic applications.

VAGN SELE

Central Hospital

Whitehead, M I, and Campbell, S, in Proceedings of the Second International Mecting on Endometrial Cancer and Related Topics, ed R W Taylor, M Brush and $R$ J King. London, Bailliere, Tindall and

$1973,20,123$. Holt, E M, Fournal of Obstetrics and Gynaecology of
the British Commontealth, 1970, 77, 1043.

\section{Diet and asthma}

SIR,-I should like to modify the impressions created by your leading article on this subject (18 March, p 669) - namely, that food allergy is rare except when caused by chemicals and dyes and that it does not merit the clinician's careful attention. You also suggest that only $15^{\circ}$. of asthmatic children show positive reactions to skin tests.

The punch-card records of 170 unselected children with bronchial asthma under 15 years of age seen by myself were examined. Of these, $147\left(86.5^{\circ}{ }^{\circ}\right)$ showed positive skin responses to prick tests with common allergens. Twenty-one children $\left(12 \cdot 3^{\circ}{ }_{0}\right)$ were thought at the first interview to suffer from clinically relevant food allergies. Of this group only six gave positive skin tests to foods, although 18 had the usual positive skin-test responses to inhalant allergens manifested by atopics. On the other hand in the original group of 170 children $22\left(15^{\circ}{ }_{11}\right)$ gave positive skin-test responses to foods at the initial interview but were thought not to be suffering from clinical food allergy. Of a similar random group of 250 asthmatic adults $204\left(81 \cdot 6^{\circ}{ }_{0}\right)$ had positive prick tests to common inhalant allergens. Forty adults $\left(16^{\prime \prime}\right)$ were at initial interview thought to be clinically food sensitive, but only nine of these $\left(3 \cdot 6^{\prime \prime}\right.$ " of the total sample) had positive skin tests to foods. On the other hand 43 patients $\left(17 \cdot 2^{\circ}\right)$ had positive prick tests to food without any obvious history of food allergy.

The conclusion to be drawn from the above figures is that, as in all areas of medicine, the history is paramount and it behoves us well to listen to what the patient or his relatives may tell us. Often young children are aware that foodstuffs can produce adverse effects which their parents have ignored; on the other hand even adults may not realise that some of their symptoms, whether commonplace or bizarre, may be caused by foods. Although diagnostic diets may be dull and inconvenient, they are well worth the time and effort spent on them, as they serve to reveal unsuspected food allergies in some patients but convince others that their dietary phobias are unfounded.

M A GANDERTON

Allergy Department,
St Mary's Hospital,

London $\mathrm{W} 2$

SIR,-Your leading article on diet and asthma (18 March, p 669) rightly draws attention to Freedman's important work on hypersensitivity to food additives in orange drinks as a cause of asthma. ${ }^{1}$ Unfortunately you have embellished this report with an introductory paragraph and end piece which are misleading and were not part of Freedman's original publication. Freedman carried out experimental provocation of asthmatics without the use of a placebo. Detection of the ensuing bronchospasm by spirometry (in which a 12 " "reduction of $\mathrm{FEV}_{1}$ at any time up to $30 \mathrm{~min}$ after challenge was accepted as a positive response) does not increase the objectivity of the results, which depend on conscious effort by the patient. Indeed, since tartrazine and sodium benzoate were given in three incremental doses at 40-min intervals a $12^{\circ}$ " reduction at any time in two hours would have been accepted as a positive response. Fortunately, two-thirds of the responses observed by Freedman were considerably greater than the minimum accepted.

Since you accept the validity of Freedman's work, why do you dismiss the importance of allergy to foods themselves? The innumerable publications on food allergy include many in which the methods of investigation were at least as valid as those used in Freedman's trial. Even the methodology of sublingual testing as usually practised is scarcely less objective."

I fear that it is conformity to established medical thought which has caused you to believe work on an acceptable topic but uncritically to reject equally laudable work which current medical religion regards as heresy.

L M McEWEN

Allergy Department,

St Mary's Hospital,

London W2.

' Freedman, B J, Clinical Allergy, 1977, 7, 407

Mackarness, R, Not All in the Mind. London, Pan Books, 1976

\section{Treating pressure sores}

SIR,--In your leading article (13 May, p 1232) while reviewing the different methods of treatment of pressure sores, you make no mention of Op-site dressing (a polyurethane sheet coated with low-allergy surgical adhesive). In our geriatric research unit we have treated over 40 cases with superficial sores in the past 18 months with over $90^{\circ}$ "success. The method we use is to clean the sore with half-strength physiological saline and cover it with Op-site dressing, which is changed weekly. Sores so treated heal within two weeks compared with three weeks for controls.

As you rightly point out, $70-90^{\circ} \circ$ of 